\title{
Lipopolysaccharide Simulations are Sensitive to Phosphate Charge and Ion Parameterization
}

\author{
Amy Rice, ${ }^{\dagger} \S$ Mary T. Rooney, ${ }^{\ddagger}$ Alexander I. Greenwood,,+9 Myriam L. Cotten, \\ and Jeff Wereszczynski*,† \\ $\dagger$ Department of Physics and Center for Molecular Study of Condensed Soft Matter, Illinois \\ Institute of Technology, Chicago, IL 60616, United States \\ $\ddagger$ Department of Applied Science, College of William and Mary, Williamsburg, VA 23185, \\ United States \\ \Department of Physics, College of William and Mary, Williamsburg, VA 23185, United \\ States \\ $\S$ Current address: Laboratory of Computational Biology, National Heart, Lung, and Blood \\ Institute, National Institutes of Health, Bethesda, Maryland 20892, United States \\ E-mail: jwereszc@iit.edu
}

\begin{abstract}
The high proportion of lipopolysaccharide (LPS) molecules in the outer membrane of Gram-negative bacteria make it a highly effective barrier to small molecules, antibiotic drugs, and other antimicrobial agents. Given this vital role in protecting bacteria from potentially hostile environments, simulations of LPS bilayers and outer membrane systems represent a critical tool for understanding the mechanisms of bacterial resistance and the development of new antibiotic compounds that circumvent these defenses. The basis of these simulations are parameterizations of LPS, which have been developed for all major molecular dynamics force fields. However, these parameterizations differ in both the protonation state of LPS as well as how LPS membranes behave
\end{abstract}


in the presence of various ion species. To address these discrepancies and understand the effects of phosphate charge on bilayer properties, simulations were performed for multiple distinct LPS chemotypes with different ion parameterizations in both protonated or deprotonated lipid A states. These simulations show that bilayer properties, such as the area per lipid and inter-lipid hydrogen bonding, are highly influenced by the choice of phosphate group charges, cation type, and ion parameterization, with protonated LPS and monovalent cations with modified nonbonded parameters providing the best match to experiments. Additionally, alchemical free energy simulations were performed to determine theoretical $\mathrm{pK}_{a}$ values for LPS, and subsequently validated by ${ }^{31} \mathrm{P}$ solid-state NMR experiments. Results from these complementary computational and experimental studies demonstrate that the protonated state dominates at physiological pH, contrary to the deprotonated form modeled by many LPS force fields. In all, these results highlight the sensitivity of LPS simulations to phosphate charge and ion parameters, while offering recommendations for how existing models should be updated for consistency between force fields as well as to best match experiments.

\section{Introduction}

Gram-negative bacterial infections are a significant public health threat, ${ }^{1}$ and are typically more difficult to treat than Gram-positive infections ${ }^{2-4}$ due largely to the presence of a second, outer membrane surrounding their peptidoglycan cell wall and plasma membrane. This outer membrane is highly asymmetric, containing predominately phospholipids in the inner leaflet, while the outer leaflet is rich in lipopolysaccharides (LPS). ${ }^{5,6}$ LPS are structurally dissimilar from glycerophospholipids, and are composed of three regions: lipid A, which contains multiple saturated hydrocarbon chains and acts as the hydrophobic anchor; the core region, a collection of branched oligosaccharides that are often phosphorylated; and the O-antigen, a polymer of repeating saccharide units. The large number of anionic groups present in LPS imparts a net negative charge to the molecule, and leaflets are stabilized by 
a network of divalent cations bridging these moieties. ${ }^{7,8}$

LPS modification processes, such as the PhoPQ system depicted in Figure 1, reduce this charge through adornment of the lipid A phosphate groups. ${ }^{9-11}$ In S. enterica, these modifications are activated by a variety of environmental stimuli, such as a low concentration of divalent cations, ${ }^{12,13}$ acidic conditions, ${ }^{14,15}$ hyperosmotic stress, ${ }^{16}$ or antimicrobial peptide presence, ${ }^{17,18}$ indicating that modifications may confer a survival advantage in such conditions. Additionally, previous simulations have shown that the presence of aminoarabinose disrupts the cation network, allowing direct inter-lipid hydrogen bonding to instead stabilize the leaflet and potentially reducing the reliance on divalent cations for stability. ${ }^{19}$

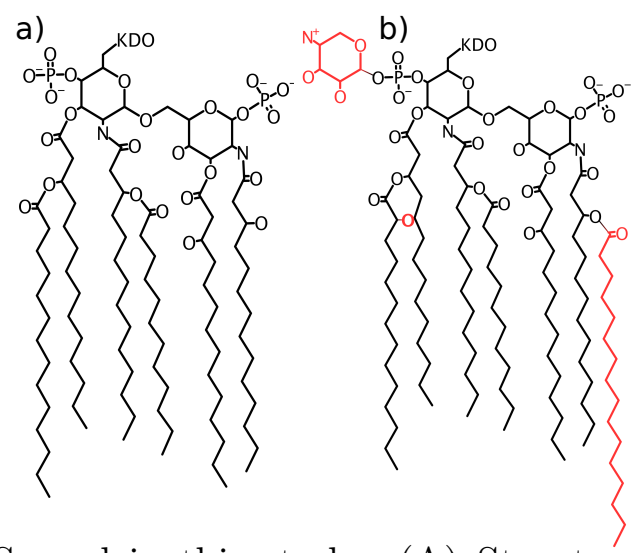

Figure 1: Structure of LPS used in this study. (A) Structure of unmodified lipid A. (B) Modification by the $P h o P Q$ regulatory system results in three key additions to the lipid A structure, shown in red. Throughout the text, we refer to LPS containing these lipid A modifications as mLPS to distinguish it from the unmodified chemotypes.

Experimentally, LPS monolayers and bilayers display significant structural changes upon monovalent or divalent cation inclusion. X-ray reflectivity experiments on Salmonella LPS exhibited a clear trend of larger lamellar repeat periods with $\mathrm{Ca}^{2+}$ and $\mathrm{Mg}^{2+}$ compared to $\mathrm{Na}^{+}$, regardless of chemotype. ${ }^{20}$ X-ray diffraction on monolayers of similar LPS species showed a much lower compressibility for monolayers with $\mathrm{Ca}^{2+}$ than those with $\mathrm{Na}^{+} .{ }^{21}$ Furthermore, monolayers of E. coli LPS revealed significantly smaller lipid areas in the presence of $20 \mathrm{mM} \mathrm{Ca}^{2+}$ with $100 \mathrm{mM} \mathrm{NaCl}$, compared to $100 \mathrm{mM} \mathrm{NaCl}$ alone or no ions, ${ }^{22}$ indicating that the type of ion species has a larger influence on the monolayer structure than the ionic strength alone. The neutron scattering density profiles of Kucerka et al. 
revealed decreased water penetration into the LPS core in $\mathrm{Ca}^{2+}$-containing LPS bilayers only, compared to those containing either $\mathrm{Na}^{+}$or $\mathrm{Mg}^{2+}$, despite the similar increased tail ordering observed with either divalent cation. ${ }^{7}$ This intriguing difference between $\mathrm{Ca}^{2+}$ and $\mathrm{Mg}^{2+}$ may be attributable to calcium's lower hydration energy than magnesium, meaning that less energy is required to remove its hydration shell. In all, these results demonstrate a clear condensing effect of divalent cations, such as $\mathrm{Ca}^{2+}$ and $\mathrm{Mg}^{2+}$, compared to $\mathrm{Na}^{+}$. This condensing effect is manifested through smaller lipid areas, decreased tail mobility, and increased molecular packing.

LPS models have been parameterized for all major families of molecular dynamics (MD) force fields, ${ }^{23-28}$ and outer membrane simulations with LPS are increasingly more common. ${ }^{29-33}$ However, the performance of common ion force fields with these LPS models has rarely been evaluated, and inconsistencies exist between different parameterizations. The GROMOS-based force field of Pontes et al., when simulated with $\mathrm{Ca}^{2+}$ or $\mathrm{Na}^{+}$, was found to only form a stable lamellar phase in the presence of $\mathrm{Ca}^{2+} ;{ }^{24}$ simulations with $\mathrm{Na}^{+}$resulted in a clear transition from lamellar to nonlamellar structures. Kim et al., utilizing the CHARMM LPS force field, ${ }^{25}$ reported a compaction upon inclusion of $\mathrm{K}^{+}$or $\mathrm{Na}^{+}$compared to $\mathrm{Ca}^{2+}$ for all five LPS chemotypes simulated, ${ }^{34}$ contrary to experiment. The closest match to experiment comes from the GLYCAM LPS ${ }^{23}$ force field- simulations of asymmetric LPS bilayers displayed a decreased lipid area with divalent cations compared to monovalent cations $;^{8}$ however, the bilayer was not stable in the presence of $\mathrm{K}^{+}$, breaking down within the first 50 ns of the simulation.

The troubling inconsistencies between these force fields may arise in part from the different ion and water models used. However, additional discrepancies exist between LPS parameterizations- there is no consensus on the charge state of phosphate groups within LPS and different force fields assign different net charges. The atomistic GLYCAM, ${ }^{23}$ GROMOSbased, ${ }^{24}$ and $\mathrm{AMBER}^{27}$ force fields, as well as MARTINI-compatible coarse grained (CG) models built off them, ${ }^{35,36}$ assign a charge state of -1 to the lipid A phosphate groups. In 
contrast to this, the CHARMM LPS force field ${ }^{25,34}$ and corresponding CG models ${ }^{26}$ treat $^{2}$ the lipid A phosphate groups as fully deprotonated, with a charge of -2 per phosphate. While no titration data exist for lamellar LPS, solubility experiments on the Re chemotyle of $E$. coli LPS determined the $\mathrm{pK}_{a}$ values in solution as 8.6 for the first lipid A deprotonation and 10.8 for the second deprotonation, ${ }^{37}$ indicating that the fully protonated state (charge of -1 per phosphate group and -4 per LPS) should dominate in solution at physiological pH.

In this study, we investigate the effects of both ion type and phosphate charge on four distinct chemotypes of S. enterica LPS (Figure 2) to better characterize these force field discrepancies as well as to study the protective effects that LPS modifications confer. We report that simulation results, such as the area per lipid, core hydration, and inter-lipid hydrogen bonding are highly influenced by the choice of protonation state, cation type, and ion parameterization. Complimentary alchemical free energy simulations and ${ }^{31} \mathrm{P}-\mathrm{NMR}$ spectroscopy experiments determine that the protonated state (-1 per phosphate group) dominates at or near physiological pH. As hypothesized, simulations with modified LPS show a decreased sensitivity to ion substitutions when compared to unmodified LPS forms. Overall, these results demonstrate the sensitivity of LPS simulations to parameterization differences and offer guidelines for how existing LPS parameterizations should be modified for better agreement with one another and experiment.

\section{Methods}

\section{System preparation}

4x4 Rc LPS bilayers were constructed by removing 20 lipids per leaflet from a pre-equilibrated 6x6 Rc LPS bilayer; this 4x4 system was then solvated and equilibrated for $2.0 \mu \mathrm{s}$. A 4x4 Rc modified LPS (mLPS) system was constructed and equilibrated in a similar manner.

No significant differences were observed between these 4x4 LPS simulations and similar 6x6 systems (Section S2 in the Supporting Information). These equilibrated 4x4 Rc systems 


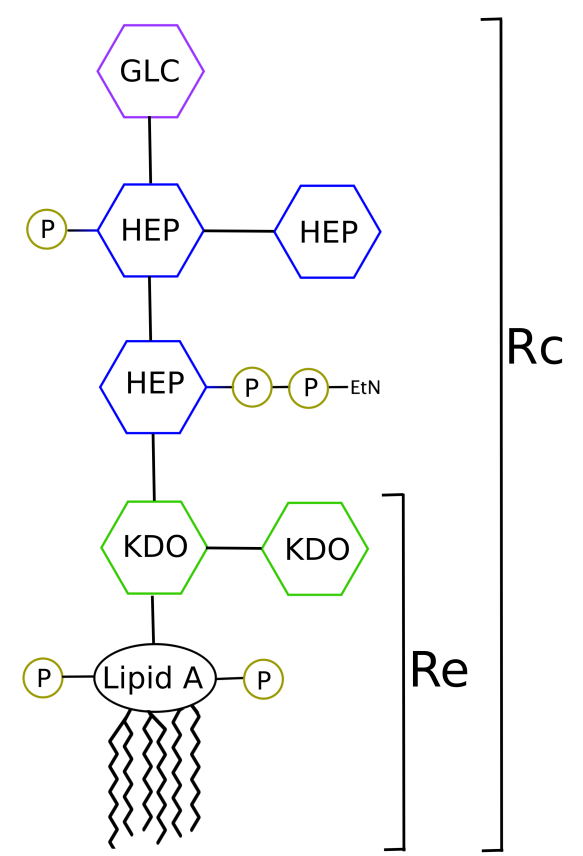

Figure 2: Schematic of the S. enterica LPS Rc core. The Re chemotype contains only the two KDO sugars. Abbreviations: KDO, 2-keto-3-deoxyoctulosonic acid; Hep, heptose; Glc, glucose; EtN, ethanolamine; P, phosphate.

were stripped of all water and ions, then resolvated with neutralizing counterions added to the bulk solvent. In all cases, enough water was added to ensure a $\sim 1.5 \mathrm{M}$ monovalent cation concentration, and the same solvent box was used for the simulations with divalent ions. We note that LPS are highly charged molecules (-9 to -4 net charge depending on the chemotype), necessitating a large number of counterions to maintain a neutral simulation box. While the initial ion concentration in bulk solvent upon system construction is quite high, these cations quickly move to saturate the LPS core within the first few nanoseconds of the solvent equilibration described below. The number of cations in the bulk solvent during the production portion of simulations is minimal for all systems studied (Figure S6).

Simulations utilized either the default CHARMM ion parameters of Beglov and Roux, ${ }^{38}$ the NBFIX calcium parameters of Roux and Rong as reported by Kim et al., ${ }^{34}$ or the CUFIX parameters of Yoo and Aksimentiev ${ }^{39}$ for all neutralizing counterions. All systems utilized the LPS parameter set of $\mathrm{Wu}$ et $a l .{ }^{25}$ with modifications treated as described previously, ${ }^{19}$ the C36 force fields for lipids, ${ }^{40,41}$ modified Lennard-Jones parameters for sodium 
ion interactions with certain lipid oxygens, ${ }^{42}$ and TIP3P water. ${ }^{43}$ Lipid A phosphate groups with a charge of -1 were parameterized by analogy to the C36 general force field, ${ }^{44}$ using methylphosphate as a template; the parameters used are given in Table S1. We note that in all Rc systems, phosphate groups in the core oligosaccharide region retained their default charge of -2 , regardless of the treatment of the lipid A phosphate group charge; Re systems do not contain any core phosphate groups. Systems were converted to AMBER-compatible format using chamber ${ }^{45}$ in ParmEd, then minimized, heated, and equilibrated for 5 ns with LPS sugars restrained to allow the water density to equilibrate. This 5 ns solvent equlibration was sufficiently long to allow hydration of the LPS core; furthermore, in all simulations the majority of counterions were associated with the LPS core by the end of this solvent equilibration.

\section{Conventional molecular dynamics simulations}

Initially, 56 different systems were simulated, accounting for all possible combinations of four LPS chemotypes, seven ion models, and two different phosphate net charges (Table 1). Four additional simulations were performed of Re LPS with -1 phosphate charges interacting with an excess of $\mathrm{Ca}^{2+}, \mathrm{K}^{+}, \mathrm{Mg}^{2+}$, or $\mathrm{Na}^{+}$to verify the results of these lower charge simulations were not a consequence of having fewer cations present (Section S1). All conventional MD (cMD) production simulations were performed with the GPU-accelerated version of pmemd in AMBER 18, ${ }^{46}$ and were carried out for 3.0 us per system. System temperatures were controlled at $310 \mathrm{~K}$ using Langevin dynamics, with a collision frequency of $1.0 \mathrm{ps}^{-1}$. The pressure was maintained at 1.0 bar by means of semi-isotropic coordinate scaling, with z decoupled from the xy dimensions, and utilized the Berendsen barostat ${ }^{47}$ with a relaxation time of 1.0 ps. All hydrogen bonds were constrained using SHAKE. ${ }^{48}$ A $12.0 \AA$ cutoff was used, with interactions smoothly switched to zero over 10-12 A. Long-range electrostatics were treated using the particle mesh Ewald (PME) method ${ }^{49}$ with a grid spacing of $1.0 \AA$. 
Table 1: Enumeration of the different system options used for cMD simulations. * Refer to Figures 1 and 2 for chemotype depictions. † Default CHARMM parameters of Beglov and Roux. ${ }^{38} \ddagger$ NBFIX calcium parameters of Roux and Rong as reported by Kim et al. ${ }^{34}$ - CUFIX parameters of Yoo and Aksimentiev. ${ }^{39}$ The exact Lennard-Jones parameters used are given in Table S6.

\begin{tabular}{lcl} 
System Feature & Number & Specification \\
\hline LPS chemotype & 4 & Rc LPS, Rc mLPS, Re LPS, Re mLPS \\
\hline \multirow{3}{*}{ Ion model } & & $\mathrm{Ca}^{2+}, \mathrm{K}^{+}, \mathrm{Mg}^{2+}, \mathrm{Na}^{+} \dagger$ \\
& 7 & $\begin{array}{l}\text { NBFIX Ca } \mathrm{Ca}^{2+} \ddagger \\
\text { CUFIX K }\end{array}$ \\
\hline Lipid A phosphate charge & 2 & $-2,-1$ \\
\hline
\end{tabular}

\section{Alchemical free energy simulations}

Alchemical free energy simulations were performed in NAMD 2.13, ${ }^{50}$ utilizing interleaved double-wide sampling to allow sampling in both the forward and reverse direction at each lambda window. Simulations were performed at fifteen windows with $\lambda=0.0,0.01,0.05,0.1$, $0.2, \ldots, 0.9,0.95,0.99,1.0$. Here,$\lambda=0.0$ corresponds to the state where the proton in question is present, while $\lambda=1.0$ corresponds to the deprotonated state. Four distinct alchemical transformations were performed: from the -4 to -5 charge state by deprotonation of either the $\mathrm{P}_{A}$ or $\mathrm{P}_{B}$ phosphate of Re LPS, and from the -5 to -6 charge state by deprotonation of the second phosphate group (Figure 3). Each of these four alchemical transformations were performed in three different environments: solvent, a fully deprotonated (-6 state) Re LPS bilayer, and a doubly protonated (-4 state) Re LPS bilayer.

Each lambda window was equilibrated for $1 \mathrm{~ns}$, followed by $10 \mathrm{~ns}$ of production MD. Soft-core vdW potentials and a delayed introduction of electrostatics (lambda $>0.1$ ) were performed to avoid infinite electrostatic or vdW interactions at end points. The bilayer simulations were performed five times each for robust error analysis, while the solvent simulations were repeated three times. 


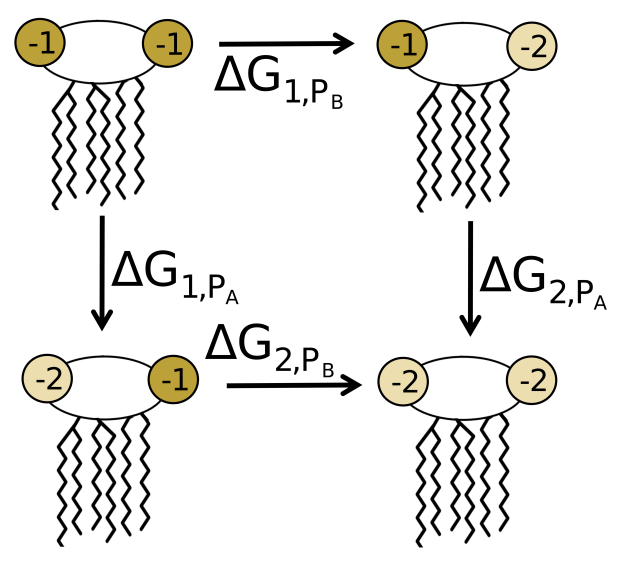

Figure 3: Depiction of the four alchemical transformation pathways explored using free energy simulations. These correspond to deprotonation of either the $\mathrm{P}_{A}$ or $\mathrm{P}_{B}$ phosphate, with the other phosphate group either protonated or deprotonated.

\section{Simulation analysis}

Trajectory analysis was performed over the final $1.0 \mu$ s of each cMD simulation, to allow ample time for bilayer equilibration. Lipid area, hydrogen bonds, carbon-deuterium order parameters, and electron density profiles along the bilayer normal were calculated using CPPTRAJ ${ }^{51}$ from AmberTools 17. ${ }^{52}$ Carbon-deuterium order parameters are reported as $\left|S_{\mathrm{CD}}\right|$. All hydrogen bond calculations utilized a distance cutoff of $3.0 \AA$ and an angle cutoff of $135^{\circ}$. Cation coordinating groups were determined using a distance-based cutoff, calculated in $\mathrm{VMD}^{53}$ and updated every 20 frames (200 ps). The cutoff used varied depending on the ion type and corresponded to the distance of the first minima in the ions' radial distribution function $(\mathrm{RDF})-3.0 \AA$ for calcium and sodium, $3.5 \AA$ for potassium, and $2.5 \AA$ for magnesium. Cation radial distribution functions (RDFs) were calculated using LOOS, ${ }^{54}$ and coordination numbers were determined by integration of the resultant RDF through the first peak. All errors are reported as standard error of the mean.

The Bennett acceptance ratio $(\mathrm{BAR})^{55}$ free energy estimator in the ParseFEP module of $\mathrm{VMD}^{56}$ was used to analyze all alchemical simulations. The full thermodynamic cycle utilized for these calculations is depicted in Figures 3 and 4 . Here, the $\Delta \mathrm{G}$ of each deproto- 
nation, either in water $\left(\Delta \mathrm{G}_{w a t}\right)$ or in the bilayer $\left(\Delta \mathrm{G}_{b i l}\right)$, is calculated from the free energy simulations with removal of a single proton. The change in energy between deprotonation in the bilayer environment and deprotonation in water is given by $\Delta \Delta \mathrm{G}=\Delta \mathrm{G}_{b i l}-\Delta \mathrm{G}_{w a t}$. From this, the $\mathrm{pK}_{a}$ shift that arises as a result of this change to the phosphate group's environment can be directly calculated:

$$
\Delta p K_{a}=p K_{a, b i l}-p K_{a, w a t}=\frac{\Delta \Delta G}{2.303 k T}
$$

where $k$ is the Boltzmann constant and $\mathrm{T}$ is the system temperature. Since the $\mathrm{pK}_{a}$ for Re LPS phosphate groups in water is known, this method allows estimation of the $\mathrm{pK}_{a}$ in the bilayer.

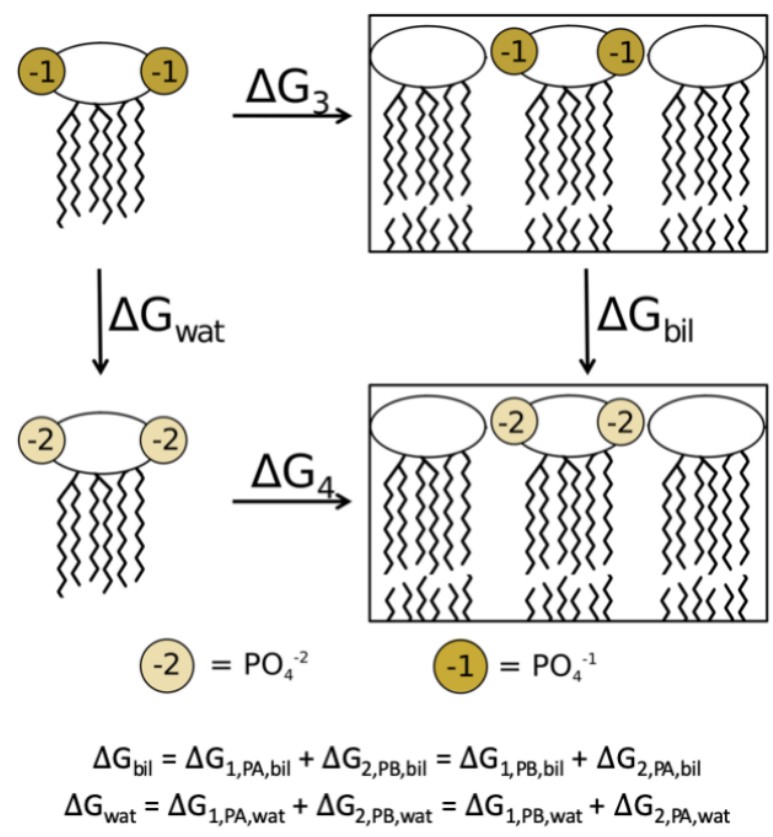

Figure 4: Thermodynamic cycle utilized in the alchemical simulations. $\Delta G_{w a t}$ and $\Delta G_{b i l}$ are calculated as the sum of the individual deprotonation steps shown in Figure 3.

\section{Experimental pH studies of LPS using solid-state NMR}

Pure LPS has been observed to form both unilamellar and multilamellar vesicles, ${ }^{57,58}$ making it suitable for ${ }^{31} \mathrm{P}$ NMR experiments. LPS E. coli strain R515, corresponding to the Re 
chemotype, was purchased from AdipoGen Life Sciences (Liestal, Switzerland) in $1 \mathrm{~mL}$ vials of sterile aqueous solution $(1 \mathrm{mg} / \mathrm{mL})$. These solutions were lyophilized, rehydrated with nanopure water, and consolidated to get 5 samples with LPS mass of $2 \mathrm{mg}$ each. The samples were then lyophilized again before resuspending to a LPS concentration of $20 \mathrm{mM}$ in $57 \mathrm{mM}$ Michaelis barbital sodium-acetate buffer ${ }^{59}$ at $\mathrm{pH} 1.99,5.02,6.99,8.98$, and 10.46. Solid $\mathrm{CaCl}_{2} \cdot 2 \mathrm{H}_{2} \mathrm{O}$ was added to reach a $\mathrm{Ca}^{2+}$ concentration of $50 \mathrm{mM}$. Each solution was incubated at $40^{\circ} \mathrm{C}$ for 30 minutes before packing the samples into $2.5 \mathrm{~mm}$ rotors (Bruker, Billirica, MA) or $5 \mathrm{~mm}$ glass tubes (New Era, Vineland, NJ) for NMR analysis.

All NMR experiments were performed on a 17.6 T (750 MHz) wide bore (Bruker, Billerica, MA) spectrometer with a variable temperature set to $32^{\circ} \mathrm{C}$ with a Bruker BVT-3000 temperature controller. ${ }^{31} \mathrm{P}$ experiments employed SPINAL-64 ${ }^{1} \mathrm{H}$ decoupling ${ }^{60}$ during acquisition, with a nutation frequency of $36 \mathrm{kHz}$ (MAS experiments) or $78 \mathrm{kHz}$ (static experiments). Static experiments were performed using a low-electrical field probe (Black Fox, Inc., Tallahassee, FL) and MAS experiments were carried out using a Bruker BL2.5 HX 2.5 mm MAS probe. In MAS experiments, spinning was regulated at 15,000 $\pm 10 \mathrm{~Hz}$ using a Bruker MAS II pneumatic MAS controller. The recycle delay was $2 \mathrm{~s}$ (MAS experiments) or $3 \mathrm{~s}$ (static experiments) and the $90^{\circ}$-pulse was $2.5 \mu \mathrm{s}$ (MAS experiments) or 6 us (static experiments). MAS spectra were indirectly referenced to adamantane externally, assuming the downfield peak of 38.48 ppm. ${ }^{61}$ NMR spectra were processed with $500 \mathrm{~Hz}$ (MAS experiments) or $1000 \mathrm{~Hz}$ (static experiments) exponential apodization and zero filled and left shifted prior to Fourier transformation. Spectra were then subjected to polynomial baseline subtraction. All samples exhibited signals consistent with stable lamellar structures (Figure S3), and displayed the same characteristic lineshape as that of phospholipids in the lamellar phase. ${ }^{62}$ 


\section{Results}

Average bilayer properties for all systems are given in Tables S2 and S3 in the Supporting Information. In all the measures studied, the bilayer structure and organization was greatly affected by the cation type included and the charge on the lipid A phosphate groups.

\section{Lower phosphate charges lead to bilayer compaction}

Protonation of the lipid A phosphate groups resulted in a markedly more compact, ordered bilayer, regardless of the LPS chemotype or cation type included. Simulations with $-\mathrm{PO}_{4}^{-}$ led to a lower area per lipid and a thicker hydrophobic region when compared to equivalent simulations with $-\mathrm{PO}_{4}^{2-}$ (Figure 5). For example, in the case of Re LPS the average area per lipid decreased from $164 \pm 0.4 \AA^{2}$ to $148 \pm 0.2 \AA^{2}$ with a concomitant thickening of the leaflet hydrophobic thickness from $12.8 \pm 0.1$ to $13.6 \pm 0.1 \AA$. Additionally, tail order parameters demonstrated a distinct ordering in LPS simulations when $-\mathrm{PO}_{4}^{-}$was implemented in place of the standard CHARMM $-\mathrm{PO}_{4}^{2-}$ (Figure $\mathrm{S} 4$ ); this difference was less pronounced in mLPS systems, likely due to the already increased ordering that palmitoylation confers. ${ }^{19}$ Finally, increased inter-lipid hydrogen bonding was observed in LPS systems with the reduced phosphate charge, while the change in mLPS systems was not statistically significant for this metric.

Furthermore, simulations with reduced lipid A phosphate charges resulted in a less hydrated LPS core, especially in the region of those phosphate groups (Figure S5 and Table S4); it is unclear whether this is an effect from the decreased lipid area or a result of fewer hydrated cations present in the core. However, regardless of the phosphate charge or core hydration, counterions remained strongly associated with the LPS core and were rarely present

in the bulk solvent (Figure S6). Overall, these results demonstrate that differing lipid A phosphate protonation states lead to clear structural variations in the simulation outcome. 

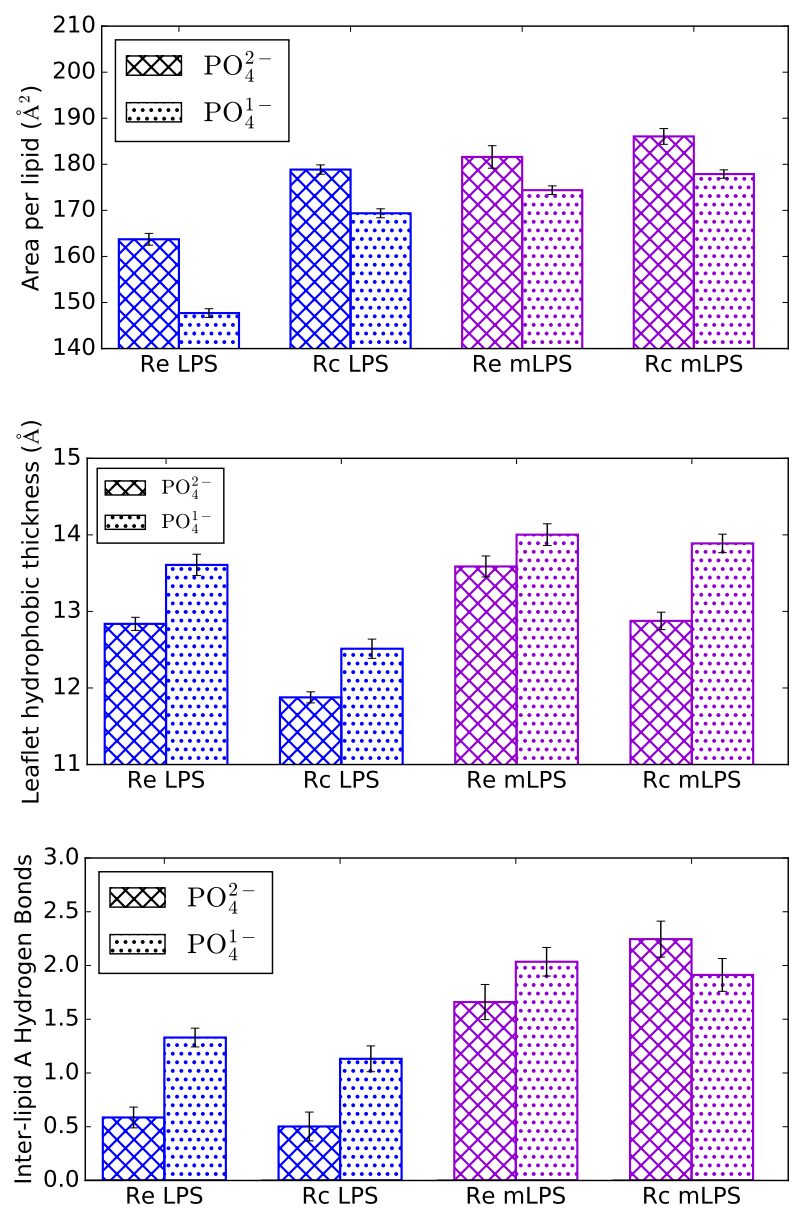

Figure 5: Effect of lipid A phosphate charge on LPS area (top), per-leaflet hydrophobic thickness (middle), and inter-lipid A hydrogen bonding (bottom). Data are shown from the simulations with $\mathrm{Ca}^{2+}$. 


\section{Cation type greatly affects LPS bilayer properties}

Lipid packing was surprisingly highly affected by the cation type included in the simulations. The standard CHARMM ion parameters, which include $\mathrm{Na}^{+}$NBFIX terms, resulted in simulations with $\mathrm{Mg}^{2+}$ counterions typically having the largest area per lipid, while simulations with $\mathrm{Na}^{+}$tended to form the most compact bilayer (Figure 6). This trend was roughly the same regardless of LPS type or phosphate charge. Coupled with these area per lipid changes were concomitant changes to the leaflet hydrophobic thickness and inter-lipid A hydrogen bonding, with lower lipid areas corresponding to more ordered lipid tails.

Utilization of the $\mathrm{Ca}^{2+}$ NBFIX ${ }^{34}$ and $\mathrm{Na}^{+} / \mathrm{K}^{+}$CUFIX ${ }^{39}$ parameter sets led to significantly better agreement with experimental lipid area trends. Simulations with these parameter sets, which refine cation interactions with phosphate and carboxyl oxygen atoms, correctly recover the experimentally-observed increased lipid area upon monovalent cation inclusion (Figure 7). This lipid area trend reversal is less striking in mLPS simulations; however, no experimental data exist for these LPS types, and the presence of aminoarabinose may likely alter the expected area trend. These results indicate that the $\mathrm{Na}^{+} / \mathrm{K}^{+} \mathrm{CUFIX}$ ion parameter sets may be the most appropriate for use with LPS simulations. Additionally, the observed changes unequivocally demonstrate that small modifications to specific non-bonded parameter pairs is sufficient to profoundly affect bilayer structural properties, indicating that further refinement to experiments may be possible.

\section{Modification confers resilience to ion-induced membrane changes}

Regardless of the chemotype or phosphate charge parameterization, simulations with PhoPQmediated modifications present exhibit more stable per lipid areas than those without modifications present (Figure 8). For example, in Re LPS with $-\mathrm{PO}_{4}^{-}$, the percent change to the lipid area is $5.4 \%$ upon inclusion of different cations compared to $\mathrm{Ca}^{2+}$, while the percent change is only $0.9 \%$ in Re mLPS. This trend holds for both Rc and Re chemotypes with either phosphate charge. Interestingly, the percent area change is roughly the same for each 
bioRxiv preprint doi: https://doi.org/10.1101/752188; this version posted January 22, 2020. The copyright holder for this preprint (which was not certified by peer review) is the author/funder, who has granted bioRxiv a license to display the preprint in perpetuity. It is made available under aCC-BY-NC-ND 4.0 International license.
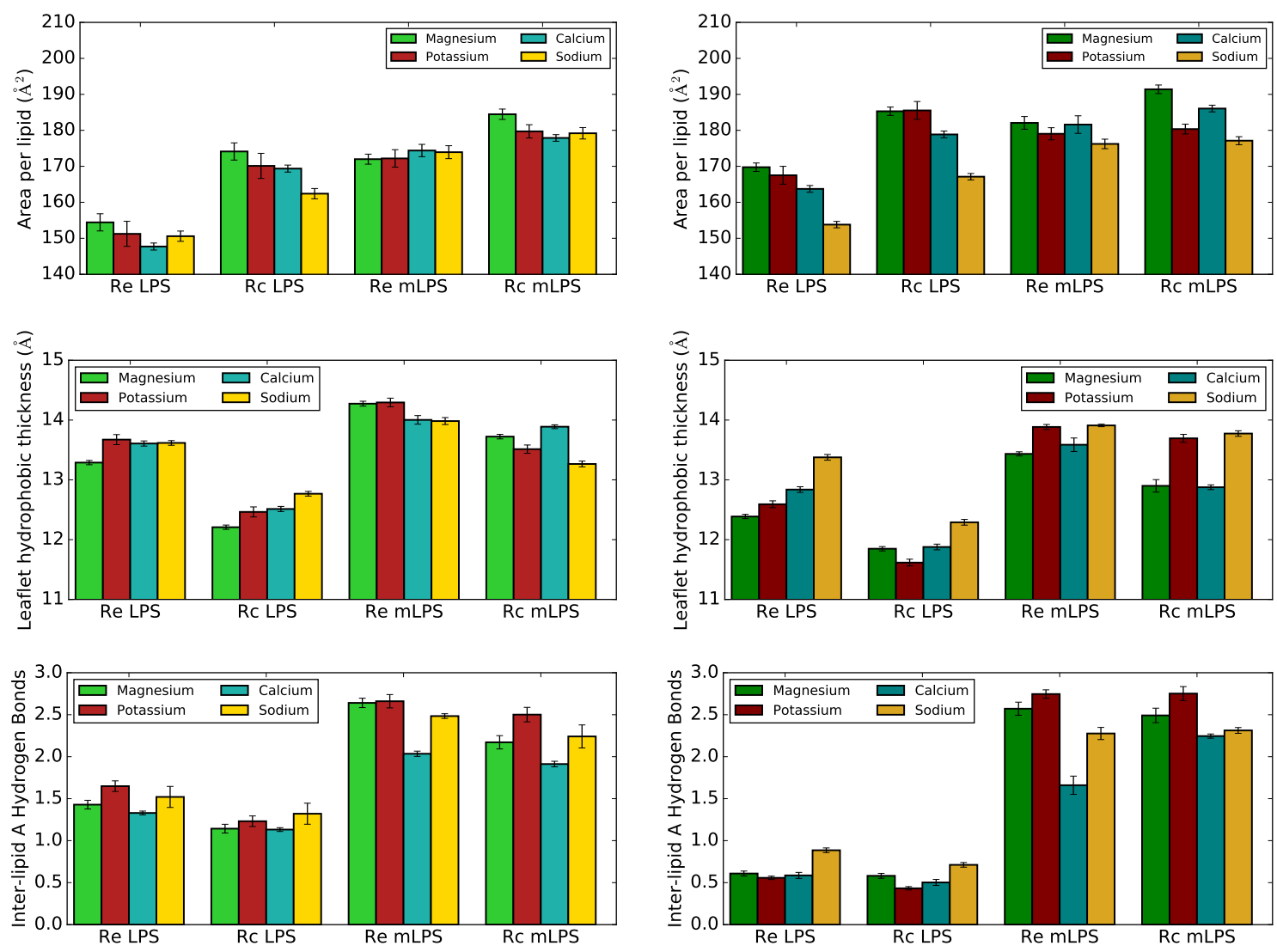

Figure 6: Effect of cation inclusion on LPS area (top), per-leaflet hydrophobic thickness (middle), and inter-lipid A hydrogen bonding (bottom). Systems with $-\mathrm{PO}_{4}^{-}$are shown on the left, while systems with $-\mathrm{PO}_{4}^{2-}$ are on the right. 
bioRxiv preprint doi: https://doi.org/10.1101/752188; this version posted January 22, 2020. The copyright holder for this preprint (which was not certified by peer review) is the author/funder, who has granted bioRxiv a license to display the preprint in perpetuity. It is made available under aCC-BY-NC-ND 4.0 International license.
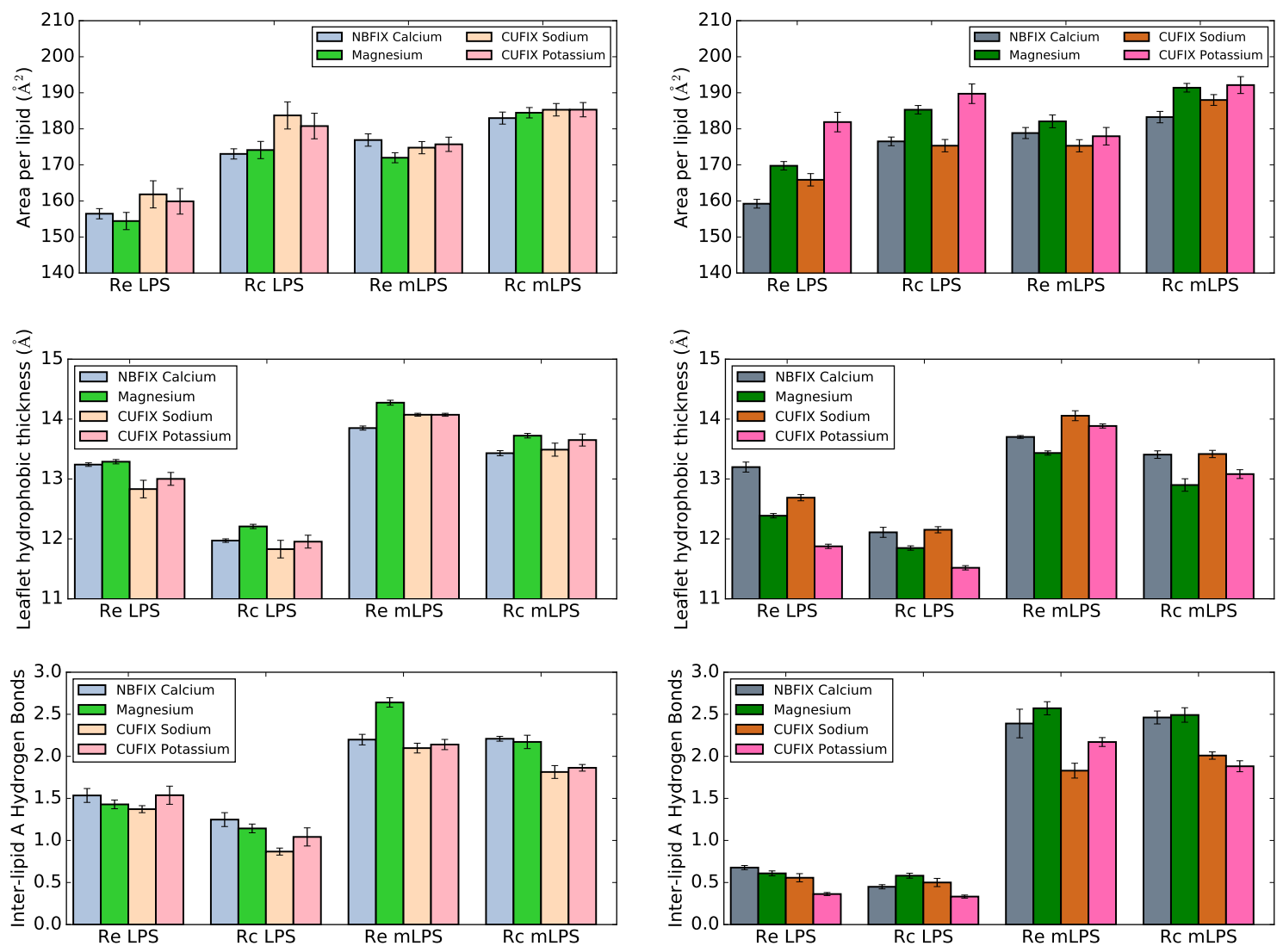

Figure 7: Effect of NBFIX/CUFIX cation inclusion on LPS area (top), per-leaflet hydrophobic thickness (middle), and inter-lipid A hydrogen bonding (bottom). Systems with $-\mathrm{PO}_{4}^{-}$ are shown on the left, while systems with $-\mathrm{PO}_{4}^{2-}$ are on the right. 
chemotype when the $-\mathrm{PO}_{4}^{-}$and $-\mathrm{PO}_{4}^{2-}$ cases are compared. Overall, these results indicate that, as hypothesized previously, ${ }^{19}$ lipid A modifications help stabilize the bilayer structure in the absence of divalent cations and may reduce reliance on these cations for stability.
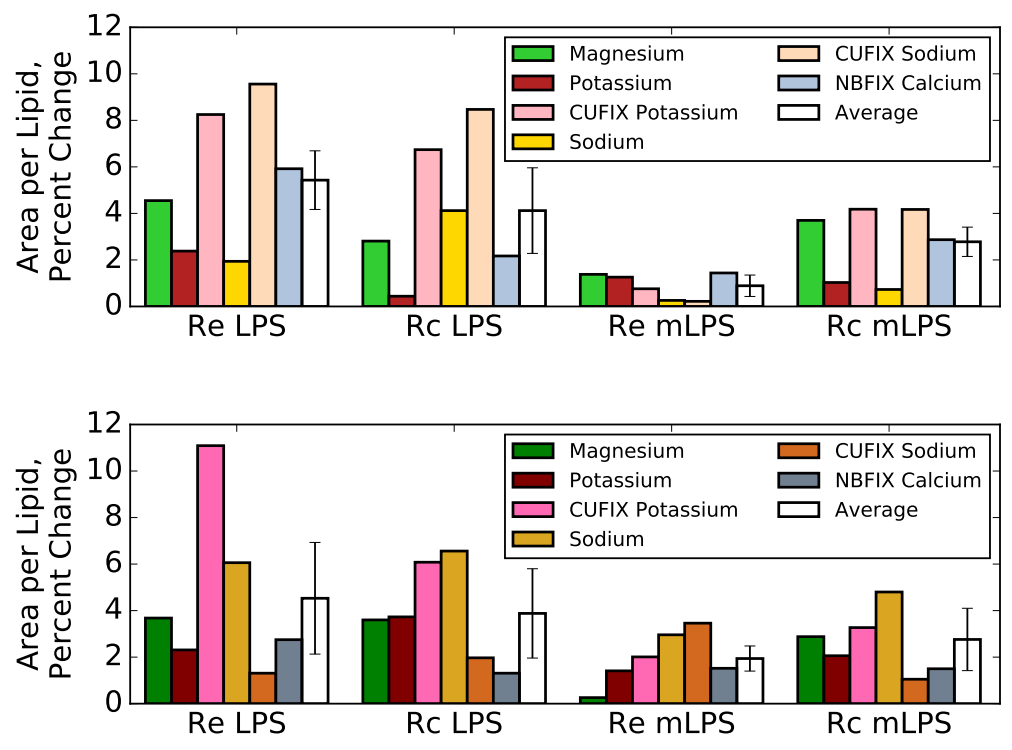

Figure 8: Percent change in area per lipid different ion species for all four chemotypes studied, compared to simulations with $\mathrm{Ca}^{2+}$ present. Systems with $\mathrm{PO}_{4}^{1-}$ are shown in the top panel, while systems with $\mathrm{PO}_{4}^{2-}$ are on the bottom.

\section{Bilayer presence shifts lipid A phosphate $\mathrm{pK}_{a}$ values}

Free energy differences for each of the four possible deprotonation steps studied (Figure 3) are given in Table S5. For each step, there was good agreement between all three or five calculation replicates performed, as indicated by the small standard errors of the mean. Additionally, energy estimates for each lambda window were well converged on the simulation timescales used here, and there were no deviations between forward and backward free energy estimates. From these $\Delta \mathrm{G}$ results, the $\Delta \Delta \mathrm{G}$ between deprotonation in the bilayer and deprotonation in solution can be calculated. These $\Delta \Delta \mathrm{G}$ values for the first (-4 to -5 charge state) and second (-5 to -6) deprotonations are given in Table 2, along with the corresponding $\mathrm{pK}_{a}$ shifts, calculated from equation 1 and the experimental data of Din et al. ${ }^{37}$ 
Table 2: Lipid A phosphate $\mathrm{pK}_{a}$ shifts and theoretical values in the bilayer, as determined by free energy simulations.

\begin{tabular}{lcccc} 
Bilayer & Charge state & $\Delta \Delta \mathrm{G}$ & $\Delta \mathrm{pK}_{a}$ & $\mathrm{pK}_{a}$, theoretical \\
\hline \multirow{2}{*}{ Protonated } & $-4 \rightarrow-5$ & $6.8 \pm 0.3$ & $4.8 \pm 0.2$ & $13.4 \pm 0.2$ \\
& $-5 \rightarrow-6$ & $7.3 \pm 0.3$ & $5.2 \pm 0.2$ & $15.9 \pm 0.2$ \\
\hline \multirow{2}{*}{ Deprotonated } & $-4 \rightarrow-5$ & $2.7 \pm 0.6$ & $1.9 \pm 0.4$ & $10.5 \pm 0.4$ \\
& $-5 \rightarrow-6$ & $1.0 \pm 0.4$ & $0.7 \pm 0.3$ & $11.5 \pm 0.3$ \\
\hline
\end{tabular}

In all cases, the $\mathrm{pK}_{a}$ shifts were positive, indicating an upward shift compared to the $\mathrm{pK}_{a}$ in solution. The resultant theoretical $\mathrm{pK}_{a}$ values were calculated as 10.5 and 11.5 for the first and second deprotonations when simulated in the deprotonated bilayer, and 13.4 and 15.9 when in the protonated bilayer. It should be noted that even a conservative reference $\mathrm{pK}_{a}$ of 6.0 , corresponding roughly to the $\mathrm{pK}_{a}$ of glucose phosphate in water, ${ }^{63,64}$ would still result in lipid $\mathrm{A} \mathrm{pK}_{a}$ values for the first deprotonation well above physiological $\mathrm{pH}-10.8$ in the protonated bilayer and 7.9 in the deprotonated bilayer.

\section{NMR validates protonated LPS charge state}

Given the large differences in simulated membrane properties between different LPS protonation states, experimental validation of the predicted $\mathrm{pK}_{a}$ values is critical for informing force field paramaterizations. ${ }^{31} \mathrm{P}$ NMR spectroscopy is sensitive to phosphate protonation state and the $\mathrm{pH}$-dependence of chemical shifts can be used to determine $\mathrm{pK}_{a}$ values. ${ }^{65}$ Magic angle spinning (MAS) ${ }^{31}$ P-NMR spectra for Re LPS show similar chemical shifts at $\mathrm{pH}$ 5.0, 7.0, and 9.0 (Figure 9) with peak positions around 1.3-1.4 ppm, demonstrating that no significant protonation state changes occur in this $\mathrm{pH}$ range. The spectra at $\mathrm{pH} 2.0$ and 10.5, however, are shifted relative to the spectra at these intermediate $\mathrm{pH}$ values, with peak locations at -0.2 and $2.7 \mathrm{ppm}$, respectively. These chemical shift perturbations indicate changes in chemical environment for the phosphate groups at these extreme pHs, with $\mathrm{pK}_{1}$ between 2.0 and 5.0, and $\mathrm{pK}_{2}$ between 9.0 and 10.5 (highlighted regions in Figure 9B).

We propose $\mathrm{pK}_{1}$ represents the first ionization of the phosphate groups, from neutral 
to anionic, while $\mathrm{pK}_{2}$ represents the second ionization. The alternative, that the lipid A phosphate groups are deprotonated and have $\mathrm{pK}_{a}$ values significantly lower than 5.0, is unlikely given that $\mathrm{pK}_{1}$ and $\mathrm{pK}_{2}$ of glucose phosphate are 1.0 and $6.1 .{ }^{63,64}$ Furthermore, our interpretation of $\mathrm{pK}_{1}$ and $\mathrm{pK}_{2}$ is consistent with the known protonation state of Re LPS in solution as physiological $\mathrm{pH},{ }^{37}$ and in good agreement with the predicted $\mathrm{pK}_{a} \sim 10.5$ from free energy simulations, while conventional simulations with singly-deprotonated LPS provide the best match to experimental structural data.
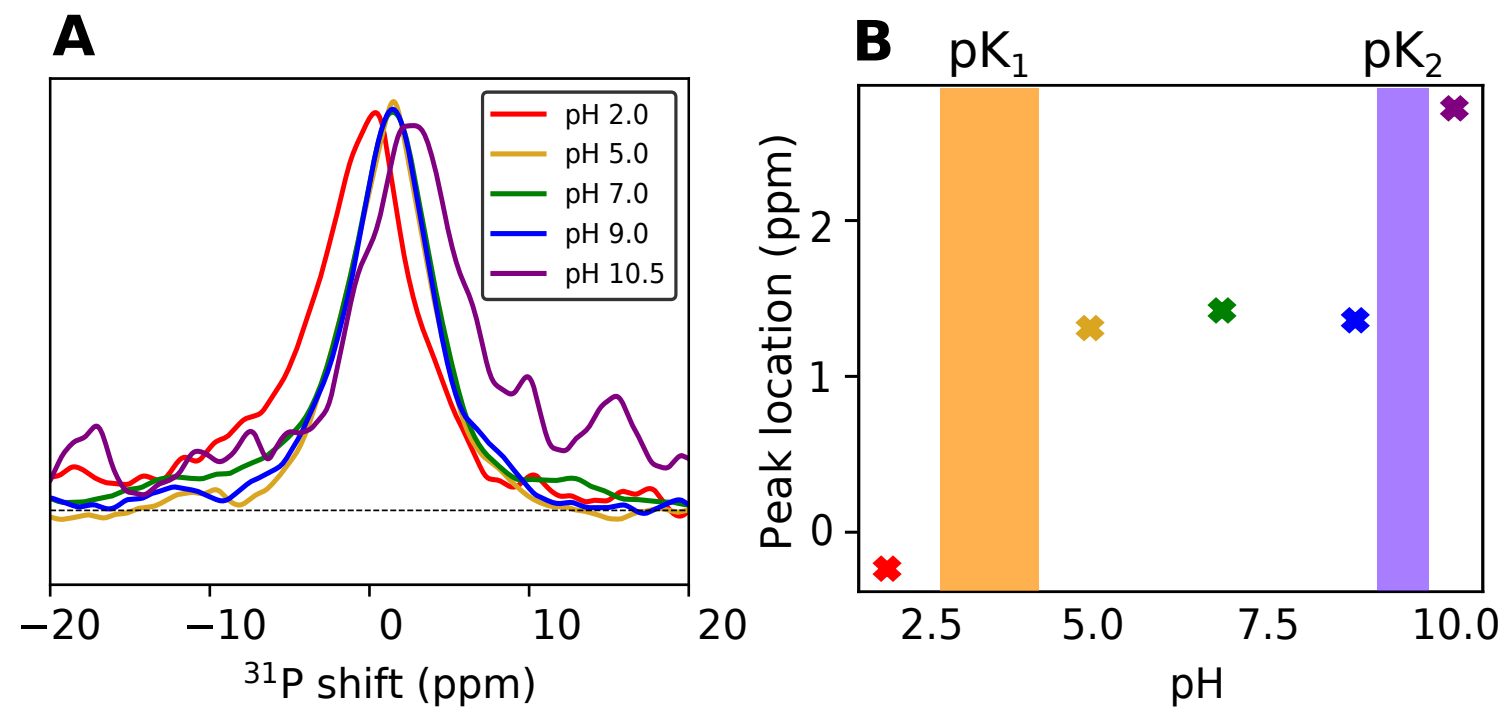

Figure 9: ${ }^{31} \mathrm{P}$ NMR pH titration of LPS. (A) ${ }^{31} \mathrm{P}$ MAS spectra of LPS as a function of $\mathrm{pH}$. Spectra of samples at five $\mathrm{pH}$ values are overlaid. (B) ${ }^{31} \mathrm{P}$ peak position (in ppm) plotted as a function of sample $\mathrm{pH}$. The two shaded regions indicate the putative approximate values for $\mathrm{pK}_{1}$ and $\mathrm{pK}_{2}$.

\section{Discussion}

Discrepancies exist between the commonly-used LPS force fields, both in the lipid A phosphate group charges and in the bilayer response to the inclusion of different ions. The CHARMM LPS force field assigns a -2 net charge to each phosphate group ${ }^{25}$ and displays significant compaction upon monovalent cation inclusion compared to divalent cations. ${ }^{34}$ The GLYCAM LPS ${ }^{23}$ force field, on the other hand, models the phosphate groups as protonated 
(-1 charge) and correctly recovers the experimentally-observed condensing effect of divalent cations. In addition to the charge discrepancy, these force fields utilize different ion and water models as well.

In this work, we sought to understand the effects that altering the lipid A phosphate charges and including different ion parameterizations have on the structural characteristics of LPS simulations. Regardless of the phosphate charge utilized, use of the default CHARMM ion parameters ${ }^{38}$ with the standard sodium NBFIX terms ${ }^{42}$ resulted in smaller lipid areas with $\mathrm{Na}^{+}$than $\mathrm{Ca}^{2+}$, in agreement with the simulation results of Kim et al. ${ }^{34}$ This indicates that the differences in LPS response to ions between force fields cannot be attributed to the differing charge state alone, and that the ion or water parameters themselves are responsible. Indeed, implementation of the sodium/potassium CUFIX ${ }^{39}$ was sufficient in most systems to recover the expected trend of increased area and fluidity with monovalent cations.

Distinct differences were also observed between simulations with charges of -1 and -2 per lipid A phosphate group. Inter-lipid A hydrogen bonding was greatly increased for unmodified LPS systems when the protonated lipid A phosphates were utilized; this effect is likely a result of the additional hydrogen bond donors present in these systems. Furthermore, protonation of the phosphate groups had a condensing effect (Figures 5 and S4), especially striking in the LPS chemotypes. This decreased area per lipid resulted in more ordered, tightly packed lipid tails; the area per tail observed was 24.5-26.5 $\AA^{2}$ for Re LPS with protonated phosphate groups, compared to 26.5-30.5 $\AA^{2}$ for fully deprotonated Re LPS. These smaller lipid tail areas are in better agreement with measurements by Snyder et al., which places the upper limit for the area per lipid tail at $26 \AA^{2}$ for liquid-crystalline LPS. ${ }^{20}$ Though no experimental per lipid areas for the Rc or Re chemotypes could be found, the per lipid areas of $169 \AA^{2}$ and $184 \AA^{2}$ for protonated Rc LPS with $\mathrm{Ca}^{2+}$ and CUFIX $\mathrm{Na}^{+}$are more consistent with the experimentally determined areas of $168.6 \pm 1.4 \AA^{2}$ for the Ra chemotype with $\mathrm{Ca}^{2+}$ and $207.8 \pm 4.9 \AA^{2}$ with $\mathrm{Na}^{+},{ }^{66}$ compared to 179 and $175 \AA^{2}$ in the corresponding deprotonated simulations. We note that, since the Ra chemotype contains more core sugars, 
the areas per lipid for the Rc chemotype are likely smaller than the experimental areas cited above. Overall, simulations demonstrate that models with protonated lipid A form more compact bilayers, which may represent a better match to the liquid-crystalline phase the outer membrane is believed to adopt physiologically. ${ }^{5,67}$

Determination of the physiologically-relevant lipid A phosphate charge representation is a crucial problem that simulations need to address, especially in light of these differences observed between simulations with protonated or deprotonated lipid A phosphate groups. Here, free energy simulations were utilized to alchemically predict the $\mathrm{pK}_{a}$ shift in the bilayer compared to solution, while ${ }^{31} \mathrm{P}-\mathrm{NMR}$ verified protonation state predictions. These results indicate that many LPS models, such as those utilized by the CHARMM-GUI and CG models based off it, incorrectly assign a charge of -2 to both lipid A phosphate groups which leads to significantly different bilayer properties. Furthermore, this charge assignment, especially when coupled with the strong nonbonded interactions of the CHARMM ions with oxygen, likely overestimates the affinity of cation binding. Since many AMPs are believed to competitively displace cations from the LPS core,${ }^{68-70}$ overly-stabilized cation interactions could have a significant effect on the outcome of such simulations.

Based on these results, we recommend that current LPS force field parameterizations be updated to correct for these charge inaccuracies, and offer the following phosphate charge guidelines: (1) At or near physiological pH, each LPS lipid A phosphate group should carry a charge of -1. (2) Phosphate groups adorned with positively-charged chemical modifications (AAB, PEtN, etc) should also carry a charge of -1. (3) Phosphate groups in the core, such as heptose- 5 phosphate in the Re chemotype, are currently represented by a default charge of -2 ; future work is needed to definitively determine the appropriate protonation states of these groups. Furthermore, based on simulations with different ion parameterizations, we recommend use of the $\mathrm{Na}^{+} / \mathrm{K}^{+}$CUFIX ${ }^{39}$ ion parameter sets when utilizing the CHARMM LPS force field for best agreement with experimental data. Finally, recent studies of phospholipids have revealed an overestimation of head group charge-charge interactions, which 
can lead to significant differences in bilayer properties; ${ }^{71}$ while this study examined only the ion-phosphate interaction, LPS simulations may suffer from similar overestimation, and refinement of both intra-lipid and lipid-ion nonbonded parameters represent promising approaches for further model improvement. Additional calcium non-bonded refinement has occurred since the start of this work, ${ }^{72}$ which may provide better agreement with experiment. Altogether, these results highlight inconsistencies in the current LPS models, while offering guidelines for choosing appropriate models to better reproduce experimental LPS results.

\section{Acknowledgement}

The authors thank Prof. James Gumbart for helpful and constructive discussions concerning this work. Research reported in this publication was supported by the National Institute of General Medical Sciences of the National Institutes of Health (grant 1R35GM119647). The content is solely the responsibility of the authors and does not necessarily represent the official views of the National Institutes of Health. This work used the Extreme Science and Engineering Discovery Environment (XSEDE), ${ }^{73}$ Comet at the San Diego Supercomputer Center at UC San Diego through allocation TG-MCB140081.

\section{Supporting Information Available}

Supplementary data analysis, tables, figures, and atomic partial charges for protonated lipid A phosphate groups.

\section{References}

(1) World Health Organization, Antimicrobial resistance: global report on surveillance, 2014. 2014. 
(2) Delcour, A. H. Outer membrane permeability and antibiotic resistance. Biochim. Biophys. Acta 2009, 1794, 808-816.

(3) Blair, J. M.; Webber, M. A.; Baylay, A. J.; Ogbolu, D. O.; Piddock, L. J. Molecular mechanisms of antibiotic resistance. Nat. Rev. Microbiol. 2015, 13, 42-51.

(4) Miller, S. I. Antibiotic Resistance and Regulation of the Gram-Negative Bacterial Outer Membrane Barrier by Host Innate Immune Molecules. MBio 2016, 7.

(5) Nikaido, H. Molecular basis of bacterial outer membrane permeability revisited. Microbiol Mol Biol Rev 2003, 67, 593-656.

(6) Silhavy, T. J.; Kahne, D.; Walker, S. The bacterial cell envelope. Cold Spring Harb Perspect Biol 2010, 2, a000414.

(7) Kucerka, N.; Papp-Szabo, E.; Nieh, M. P.; Harroun, T. A.; Schooling, S. R.; Pencer, J.; Nicholson, E. A.; Beveridge, T. J.; Katsaras, J. Effect of cations on the structure of bilayers formed by lipopolysaccharides isolated from Pseudomonas aeruginosa PAO1. J Phys Chem B 2008, 112, 8057-8062.

(8) Nascimento, A.; Pontes, F. J.; Lins, R. D.; Soares, T. A. Hydration, ionic valence and cross-linking propensities of cations determine the stability of lipopolysaccharide (LPS) membranes. Chem. Commun. (Camb.) 2014, 50, 231-233.

(9) Raetz, C. R.; Reynolds, C. M.; Trent, M. S.; Bishop, R. E. Lipid A modification systems in gram-negative bacteria. Annu. Rev. Biochem. 2007, 76, 295-329.

(10) Miller, S. I.; Ernst, R. K.; Bader, M. W. LPS, TLR4 and infectious disease diversity. Nat. Rev. Microbiol. 2005, 3, 36-46.

(11) Needham, B. D.; Trent, M. S. Fortifying the barrier: the impact of lipid A remodelling on bacterial pathogenesis. Nat. Rev. Microbiol. 2013, 11, 467-481. 
(12) Garcia Vescovi, E.; Soncini, F. C.; Groisman, E. A. Mg2+ as an extracellular signal: environmental regulation of Salmonella virulence. Cell 1996, 84, 165-174.

(13) Bourret, T. J.; Liu, L.; Shaw, J. A.; Husain, M.; Vazquez-Torres, A. Magnesium homeostasis protects Salmonella against nitrooxidative stress. Sci Rep 2017, 7, 15083.

(14) Bearson, B. L.; Wilson, L.; Foster, J. W. A low pH-inducible, PhoPQ-dependent acid tolerance response protects Salmonella typhimurium against inorganic acid stress. J. Bacteriol. 1998, 180, 2409-2417.

(15) Prost, L. R.; Daley, M. E.; Le Sage, V.; Bader, M. W.; Le Moual, H.; Klevit, R. E.; Miller, S. I. Activation of the bacterial sensor kinase PhoQ by acidic pH. Mol. Cell 2007, 26, 165-174.

(16) Yuan, J.; Jin, F.; Glatter, T.; Sourjik, V. Osmosensing by the bacterial PhoQ/PhoP two-component system. Proc. Natl. Acad. Sci. U.S.A. 2017, 114, E10792-E10798.

(17) Bader, M. W.; Sanowar, S.; Daley, M. E.; Schneider, A. R.; Cho, U.; Xu, W.; Klevit, R. E.; Le Moual, H.; Miller, S. I. Recognition of antimicrobial peptides by a bacterial sensor kinase. Cell 2005, 122, 461-472.

(18) Martynowycz, M.; Rice, A.; Andreev, K.; Nobre, T.; Kuzmenko, I.; Wereszczynski, J.; Gidalevitz, D. Salmonella Membrane Structural Remodeling Increases Resistance to Antimicrobial Peptide LL-37. ACS Infect Dis 2019, 13088-13093.

(19) Rice, A.; Wereszczynski, J. Atomistic Scale Effects of Lipopolysaccharide Modifications on Bacterial Outer Membrane Defenses. Biophys. J. 2018, 114, 1389-1399.

(20) Snyder, S.; Kim, D.; McIntosh, T. J. Lipopolysaccharide bilayer structure: effect of chemotype, core mutations, divalent cations, and temperature. Biochemistry 1999, 38, $10758-10767$. 
(21) Jeworrek, C.; Evers, F.; Howe, J.; Brandenburg, K.; Tolan, M.; Winter, R. Effects of specific versus nonspecific ionic interactions on the structure and lateral organization of lipopolysaccharides. Biophys. J. 2011, 100, 2169-2177.

(22) Micciulla, S.; Gerelli, Y.; Schneck, E. Structure and Conformation of Wild-Type Bacterial Lipopolysaccharide Layers at Air-Water Interfaces. Biophys. J. 2019, 116, 1-11.

(23) Kirschner, K. N.; Lins, R. D.; Maass, A.; Soares, T. A. A Glycam-Based Force Field for Simulations of Lipopolysaccharide Membranes: Parametrization and Validation. $J$ Chem Theory Comput 2012, 8, 4719-4731.

(24) Pontes, F. J.; Rusu, V. H.; Soares, T. A.; Lins, R. D. The Effect of Temperature, Cations, and Number of Acyl Chains on the Lamellar to Non-Lamellar Transition in Lipid-A Membranes: A Microscopic View. J Chem Theory Comput 2012, 8, 3830-3838.

(25) Wu, E. L.; Engstrom, O.; Jo, S.; Stuhlsatz, D.; Yeom, M. S.; Klauda, J. B.; Widmalm, G.; Im, W. Molecular dynamics and NMR spectroscopy studies of E. coli lipopolysaccharide structure and dynamics. Biophys $J$ 2013, 105, 1444-1455.

(26) Hsu, P. C.; Bruininks, B. M. H.; Jefferies, D.; Cesar Telles de Souza, P.; Lee, J.; Patel, D. S.; Marrink, S. J.; Qi, Y.; Khalid, S.; Im, W. CHARMM-GUI Martini Maker for modeling and simulation of complex bacterial membranes with lipopolysaccharides. J Comput Chem 2017, 38, 2354-2363.

(27) Li, A.; Schertzer, J. W.; Yong, X. Molecular dynamics modeling of Pseudomonas aeruginosa outer membranes. Phys Chem Chem Phys 2018, 20, 23635-23648.

(28) Baltoumas, F. A.; Hamodrakas, S. J.; Iconomidou, V. A. The gram-negative outer membrane modeler: Automated building of lipopolysaccharide-rich bacterial outer membranes in four force fields. J Comput Chem 2019, 
(29) Parkin, J.; Chavent, M.; Khalid, S. Molecular Simulations of Gram-Negative Bacterial Membranes: A Vignette of Some Recent Successes. Biophys. J. 2015, 109, 461-468.

(30) Balusek, C.; Gumbart, J. C. Role of the Native Outer-Membrane Environment on the Transporter BtuB. Biophys. J. 2016, 111, 1409-1417.

(31) Patel, D. S.; Qi, Y.; Im, W. Modeling and simulation of bacterial outer membranes and interactions with membrane proteins. Curr. Opin. Struct. Biol. 2017, 43, 131-140.

(32) Boags, A.; Hsu, P. C.; Samsudin, F.; Bond, P. J.; Khalid, S. Progress in Molecular Dynamics Simulations of Gram-Negative Bacterial Cell Envelopes. J Phys Chem Lett 2017, 8, 2513-2518.

(33) Lundquist, K.; Bakelar, J.; Noinaj, N.; Gumbart, J. C. C-terminal kink formation is required for lateral gating in BamA. Proc Natl Acad Sci 2018, 115, E7942-E7949.

(34) Kim, S.; Patel, D. S.; Park, S.; Slusky, J.; Klauda, J. B.; Widmalm, G.; Im, W. Bilayer Properties of Lipid A from Various Gram-Negative Bacteria. Biophys. J. 2016, 111, $1750-1760$.

(35) Ma, H.; Irudayanathan, F. J.; Jiang, W.; Nangia, S. Simulating Gram-Negative Bacterial Outer Membrane: A Coarse Grain Model. J Phys Chem B 2015, 119, 14668-14682.

(36) Van Oosten, B.; Harroun, T. A. A MARTINI extension for Pseudomonas aeruginosa PAO1 lipopolysaccharide. J. Mol. Graph. Model. 2016, 63, 125-133.

(37) Din, Z. Z.; Mukerjee, P.; Kastowsky, M.; Takayama, K. Effect of pH on solubility and ionic state of lipopolysaccharide obtained from the deep rough mutant of Escherichia coli. Biochemistry 1993, 32, 4579-4586.

(38) Beglov, D.; Roux, B. Finite representation of an infinite bulk system: Solvent boundary potential for computer simulations. J Chem Phys 1994, 100, 9050-9063. 
(39) Yoo, J.; Aksimentiev, A. Improved Parametrization of $\mathrm{Li}+, \mathrm{Na}+, \mathrm{K}+$, and $\mathrm{Mg} 2+$ Ions for All-Atom Molecular Dynamics Simulations of Nucleic Acid Systems. J. Phys. Chem. Lett 2012, 3, 45-50.

(40) Klauda, J. B.; Venable, R. M.; Freites, J. A.; O’Connor, J. W.; Tobias, D. J.; Mondragon-Ramirez, C.; Vorobyov, I.; MacKerell, A. D.; Pastor, R. W. Update of the CHARMM all-atom additive force field for lipids: validation on six lipid types. $J$ Phys Chem B 2010, 114, 7830-7843.

(41) Pastor, R. W.; Mackerell, A. D. Development of the CHARMM Force Field for Lipids. J Phys Chem Lett 2011, 2, 1526-1532.

(42) Venable, R. M.; Luo, Y.; Gawrisch, K.; Roux, B.; Pastor, R. W. Simulations of anionic lipid membranes: development of interaction-specific ion parameters and validation using NMR data. J Phys Chem B 2013, 117, 10183-10192.

(43) Jorgensen, W.; Chandrasekhar, J.; Madura, J.; Impey, R.; Klein, M. Comparison of simple potential functions for simulating liquid water. J Chem Phys 1983, 79, 926935.

(44) Vanommeslaeghe, K.; Hatcher, E.; Acharya, C.; Kundu, S.; Zhong, S.; Shim, J.; Darian, E.; Guvench, O.; Lopes, P.; Vorobyov, I.; Mackerell, A. D. CHARMM general force field: A force field for drug-like molecules compatible with the CHARMM all-atom additive biological force fields. J Comput Chem 2010, 31, 671-690.

(45) Crowley, M.; Williamson, M.; Walker, R. CHAMBER: Comprehensive support for CHARMM force fields within the AMBER software. Int J Quantum Chem 2009, 109, 3767-3772.

(46) Case, D. A.; Cheatham, T. E.; Darden, T.; Gohlke, H.; Luo, R.; Merz, K. M.; Onufriev, A.; Simmerling, C.; Wang, B.; Woods, R. J. The Amber biomolecular simulation programs. J Comput Chem 2005, 26, 1668-1688. 
(47) Berendsen, H. J. C.; Postma, J. P. M.; van Gunsteren, W. F.; DiNola, A.; Haak, J. R. Molecular dynamics with coupling to an external bath. The Journal of Chemical Physics 1984, 81, 3684-3690.

(48) Krautler, V.; Van Gunsteren, W. F.; Hunenberger, P. H. A fast SHAKE: Algorithm to solve distance constraint equations for small molecules in molecular dynamics simulations. J Comput Chem 2001, 22, 501-508.

(49) Darden, T.; York, D.; Pedersen, L. Particle mesh Ewald - an N.log(N) method for Ewald sums in large systems. J Chem Phys 1993, 98, 10089-10092.

(50) Phillips, J. C.; Braun, R.; Wang, W.; Gumbart, J.; Tajkhorshid, E.; Villa, E.; Chipot, C.; Skeel, R. D.; Kale, L.; Schulten, K. Scalable molecular dynamics with NAMD. J Comput Chem 2005, 26, 1781-1802.

(51) Roe, D. R.; Cheatham, T. E. PTRAJ and CPPTRAJ: Software for Processing and Analysis of Molecular Dynamics Trajectory Data. J Chem Theory Comput 2013, 9, $3084-3095$.

(52) Case, D.; Cerutti, D.; T.E. Cheatham, I.; Darden, T.; Duke, R.; Giese, T.; Gohlke, H.; Goetz, A.; Greene, D.; Homeyer, N.; Izadi, S.; Kovalenko, A.; Lee, T.; LeGrand, S.; Li, P.; Lin, C.; Liu, J.; Luchko, T.; Luo, R.; Mermelstein, D.; Merz, K.; Monard, G.; Nguyen, H.; I. Omelyan, A. O.; Pan, F.; Qi, R.; Roe, D.; Roitberg, A.; Sagui, C.; Simmerling, C.; Botello-Smith, W.; Swails, J.; Walker, R.; Wang, J.; Wolf, R.; Wu, X.; Xiao, L.; York, D.; Kollman, P. AMBER17. 2017; University of California, San Francisco.

(53) Humphrey, W.; Dalke, A.; Schulten, K. VMD - Visual Molecular Dynamics. Journal of Molecular Graphics 1996, 14, 33-38.

(54) Romo, T. D.; Grossfield, A. LOOS: an extensible platform for the structural analysis of simulations. Conf Proc IEEE Eng Med Biol Soc 2009, 2009, 2332-2335. 
(55) Shirts, M.; Chodera, J. Statistically optimal analysis of samples from multiple equilibrium states. J Chem Phys 2008, 129, 124105.

(56) Liu, P.; Dehez, F.; Cai, W.; Chipot, C. A Toolkit for the Analysis of Free-Energy Perturbation Calculations. J Chem Theory Comput 2012, 8, 2606-2616.

(57) Tong, J.; McIntosh, T. J. Structure of supported bilayers composed of lipopolysaccharides and bacterial phospholipids: raft formation and implications for bacterial resistance. Biophys. J. 2004, 86, 3759-3771.

(58) Bhunia, A.; Mohanram, H.; Domadia, P. N.; Torres, J.; Bhattacharjya, S. Designed beta-boomerang antiendotoxic and antimicrobial peptides: structures and activities in lipopolysaccharide. J. Biol. Chem. 2009, 284, 21991-22004.

(59) Sober, H. A. Handbook of Biochemistry: Selected Data for Molecular Biology, 2nd ed.; CRC Press, 1970.

(60) Fung, B. M.; Khitrin, A. K.; Ermolaev, K. An improved broadband decoupling sequence for liquid crystals and solids. J. Magn. Reson. 2000, 142, 97-101.

(61) Morcombe, C. R.; Zilm, K. W. Chemical shift referencing in MAS solid state NMR. J. Magn. Reson. 2003, 162, 479-486.

(62) Cullis, P.; Fenske, D.; Hope, M. In Biochemistry of Lipids, Lipoproteins and Membranes; Vance, D., Vance, J., Eds.; 1996 Elsevier Science, 1996; Chapter 1.

(63) McElroy, W. D.; Glass, B. Phosphorus metabolism; Johns Hopkins Press, 1952.

(64) Van Wazer, J. R. Phosphorus and its compounds; Interscience Encyclopedias, Inc, 1958.

(65) Robitaille, P. L.; Robitaille, P. A.; Brown, G. G.; Brown, G. An analysis of the pHdependent chemical-shift behavior of phosphorus-containing metabolites. Journal of Magnetic Resonance 1991, 92, 73-84. 
(66) Hwang, H.; Paracini, N.; Parks, J. M.; Lakey, J. H.; Gumbart, J. C. Distribution of mechanical stress in the Escherichia coli cell envelope. Biochim Biophys Acta Biomembr 2018, 1860, 2566-2575.

(67) Paracini, N.; Clifton, L. A.; Skoda, M. W. A.; Lakey, J. H. Liquid crystalline bacterial outer membranes are critical for antibiotic susceptibility. Proc. Natl. Acad. Sci. U.S.A. 2018, 115, E7587-E7594.

(68) Hancock, R. E.; Chapple, D. S. Peptide antibiotics. Antimicrob. Agents Chemother. 1999, 43, 1317-1323.

(69) Hancock, R. E.; Scott, M. G. The role of antimicrobial peptides in animal defenses. Proc. Natl. Acad. Sci. U.S.A. 2000, 97, 8856-8861.

(70) Hagge, S. O.; Hammer, M. U.; Wiese, A.; Seydel, U.; Gutsmann, T. Calcium adsorption and displacement: characterization of lipid monolayers and their interaction with membrane-active peptides/proteins. BMC Biochem. 2006, 7, 15.

(71) Yoo, J.; Aksimentiev, A. Improved Parameterization of Amine-Carboxylate and AminePhosphate Interactions for Molecular Dynamics Simulations Using the CHARMM and AMBER Force Fields. J Chem Theory Comput 2016, 12, 430-443.

(72) Han, K.; Venable, R. M.; Bryant, A. M.; Legacy, C. J.; Shen, R.; Li, H.; Roux, B.; Gericke, A.; Pastor, R. W. Graph-Theoretic Analysis of Monomethyl Phosphate Clustering in Ionic Solutions. J Phys Chem B 2018, 122, 1484-1494.

(73) Towns, J.; Cockerill, T.; Dahan, M.; Foster, I.; Gaither, K.; Grimshaw, A.; Hazlewood, V.; Lathrop, S.; Lifka, D.; Peterson, G. D.; Roskies, R.; Scott, J. R.; WilkinsDiehr, N. XSEDE: Accelerating Scientific Discovery. Computing in Science Engineering 2014, 16, 62-74. 
bioRxiv preprint doi: https://doi.org/10.1101/752188; this version posted January 22, 2020. The copyright holder for this preprint (which was not certified by peer review) is the author/funder, who has granted bioRxiv a license to display the preprint in perpetuity. It is made available under aCC-BY-NC-ND 4.0 International license.

\section{For Table of Contents Only}

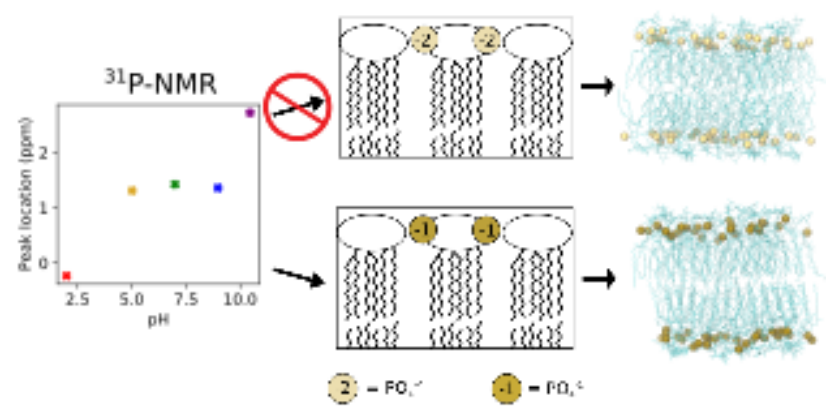

